\title{
Estabilidade do antígeno de célula total de Brucella abortus para uso no diagnóstico sorológico da brucelose bovina pela reação de fixação de complemento ${ }^{1}$
}

\author{
Luis A. Mathias ${ }^{2 *}$, Raphaella B. Meirelles ${ }^{3}$ e Fernando G. Buchala ${ }^{3}$
}

\begin{abstract}
Mathias L.A., Meirelles R.B. \& Buchala F.G. 2007. [Stability of Brucella abortus whole cell antigen for use in the serological diagnosis of bovine brucellosis by the complement fixation test.] Estabilidade do antígeno de célula total de Brucella abortus para uso no diagnóstico sorológico da brucelose bovina pela reação de fixação de complemento. Pesquisa Veterinária Brasileira 27(1):18-22. Departamento de Medicina Veterinária Preventiva e Reprodução Animal, Faculdade de Ciências Agrárias e Veterinárias (FCAV), Universidade Estadual Paulista (Unesp), Jaboticabal, SP 14884-900, Brazil. E-mail: Imathias@fcav.unesp.br

The complement fixation test is used worldwide in the confirmatory diagnosis of bovine brucellosis. For this technique the antigen is the same as the one used in the tube agglutination test. However, literature is poor in information about the stability of the whole cell Brucella antigen for use in the complement fixation test to establish a time of validity of the antigen. Hence the aim of this investigation was to evaluate the stability of this antigen under refrigeration for use in the complement fixation test. Fourteen batches of antigen prepared with Brucella abortus strain 1119/3, produced from 9 months to 23 years and 11 months before, were analysed. One hundred and sixty-seven cattle sera with varying titres of antibodies to Brucella were tested through the warm complement fixation microtechnique with five $50 \%$ haemolytic units of complement. Sera with at least $25 \%$ of complement fixation in dilution 1:4 were considered positive. The results with 13 of the antigen batches were compared with the results obtained with the batch produced 9 months before by the McNemar $\chi^{2}$ test and kappa statistic. The oldest antigen batch gave a higher proportion of sera titres which were exactly the same observed with the 9-month-batch (90.4\%), and the antigen produced 4 years and 3 months before the test gave de lowest proportion of sera with the same titre of the 9-month-antigen (73.7\%). The comparison of the results after being classified as positive and negative showed that the highest proportion of agreed results was observed with the antigen produced 21 years and 4 months before $(98.8 \%$, kappa 0.98$)$. The antigen with the lowest proportion of agreed results was the one produced 3 years and 2 months before $(91.6 \%$, kappa 0.84$)$. The results of the study show that most sera gave very similar results with all antigen batches evaluated, and that there was no relationship between the period of antigen production and the difference in test results.
\end{abstract}

INDEX TERMS: Bovine brucellosis, serological diagnosis, complement fixation test.

\footnotetext{
${ }^{1}$ Recebido para publicação em 29 de setembro de 2006.

Aceito para publicação em 10 de novembro de 2006.

Trabalho desenvolvido com auxílio financeiro da FAPESP.

${ }^{2}$ Departamento de Medicina Veterinária Preventiva e Reprodução Animal, FCAV, Unesp-Jaboticabal, Via de Acesso Prof. Paulo Donato Castellane Km 5, Jaboticabal, SP 14884-900. *Autor para correspondência: lmathias@fcav.unesp.br

${ }^{3}$ Programa de Pós-Graduação em Medicina Veterinária, FCAV, UnespJaboticabal.
}

RESUMO.- A reação de fixação de complemento é um dos testes usados no diagnóstico confirmatório da brucelose bovina, e para sua realização emprega-se o mesmo antígeno usado na prova de soroaglutinação lenta, porém não foi possível encontrar na literatura estudos sobre a estabilidade desse antígeno para uso na prova de fixação de complemento, de modo a estabelecer um prazo de validade para o mesmo. Por isso, esta investigação teve por objetivo avaliar a estabilida- 
de do antígeno de célula total de Brucella conservado sob refrigeração, para uso na reação de fixação de complemento. Analisaram-se 14 partidas de antígeno, preparado com Brucella abortus amostra 1119/3 e padronizado para uso na prova de soroaglutinação lenta, com tempo de fabricação variando de 9 meses a 23 anos e 11 meses. Testaram-se 167 soros bovinos com títulos variáveis de anticorpos contra Brucella, adotando-se a técnica com incubação a $37^{\circ} \mathrm{C}$ nas duas fases da reação e 5 unidades hemolíticas $50 \%$ de complemento. Considerou-se como positivo o soro com pelo menos $25 \%$ de fixação de complemento na diluição 1:4. Compararam-se os resultados obtidos com as 13 partidas de antígeno com aqueles obtidos com a partida com 9 meses de fabricação, usando o teste de $\chi^{2}$ de McNemar e o coeficiente kappa. A grande maioria dos soros apresentou resultados muito próximos quando testados com as diversas partidas de antígeno, e não se observou relação entre tempo de fabricação do antígeno e diferenças nos resultados obtidos.

TERMOS DE INDEXAÇÃO: Brucelose bovina, diagnóstico sorológico, reação de fixação de complemento.

\section{INTRODUÇÃO}

A brucelose ainda é um sério problema de saúde animal na maioria dos países. Com exceção daqueles que, após programas rigorosos, conseguiram erradicá-la ou pelo menos reduzir significativamente a taxa de prevalência, na maior parte do globo, principalmente nos países mais pobres, ainda se trata de uma questão sanitária preocupante.

No Brasil, a brucelose bovina ainda é endêmica, com taxas de prevalência mais elevadas em regiões com maior densidade de bovinos e com menores taxas de prevalência nos estados de Santa Catarina e Rio Grande do Sul (Poester et al. 2002).

Embora um diagnóstico definitivo e incontestável de brucelose possa ser obtido pelo isolamento do agente etiológico, esse procedimento é caro, demorado e exige recursos laboratoriais nem sempre disponíveis, o que inviabiliza seu uso em larga escala, como requer um programa de controle da enfermidade. Por essa razão, os programas de combate à brucelose baseiam-se no diagnóstico sorológico, recurso que permite a realização de um grande número de testes, com resultados adequados e a um custo acessível.

Pela importância da enfermidade e pela importância do diagnóstico sorológico no controle da mesma, muitas técnicas de diagnóstico surgiram ao longo da história, para uso no diagnóstico da brucelose, e continuam a surgir, como mostram os trabalhos iniciados por Nielsen et al. (1996), que desenvolveram um teste de polarização fluorescente que tem apresentado excelente desempenho. A excelência desse teste vem sendo confirmada em sucessivas pesquisas (Nielsen et al. 1998, Dajer et al. 1999, Samartino et al. 1999, McGiven et al. 2003), mas o uso dessa técnica ainda é pouco difundido em países subdesenvolvidos, pelo maior custo e pela dependência de importação de equipamentos e reagentes.

Excelentes resultados também foram obtidos com testes imunoenzimáticos competitivos (MacMillan et al. 1990,
Nielsen et al. 1995), mas os mesmos apresentam como desvantagem a falta de padronização e, no caso de uma eventual padronização, o fato de se ficar na dependência de um único fornecedor dos anticorpos monoclonais usados na preparação do conjugado.

Diante dessas dificuldades, o Programa Nacional de Controle e Erradicação da Brucelose e Tuberculose Animal, criado por meio da Instrução Normativa No.2, de 10 de janeiro de 2001 (Brasil 2001), optou pela adoção de técnicas sorológicas menos dispendiosas, o que permite o envolvimento de um número maior de laboratórios, aumentando a chance de êxito do programa.

O programa brasileiro prevê o uso seqüiencial dos testes rosa de Bengala (antígeno acidificado tamponado) como teste de triagem, sendo os soros com resultado positivo submetidos a confirmação, que pode ser realizada pela combinação da prova de soroaglutinação lenta com a prova do 2mercaptoetanol ou então pela reação de fixação de complemento.

A reação de fixação de complemento, apesar de ser uma técnica laboriosa, apresenta as vantagens de ter um custo relativamente baixo e de usar reagentes de fácil acesso, mesmo por parte de laboratórios sem muitos recursos, e sem depender da importação de equipamentos e reagentes. Além disso, apresenta um relevante histórico de serviços prestados no combate à brucelose animal, uma vez que a maioria dos países desenvolvidos que conseguiram erradicar a brucelose atingiram esse êxito usando a reação de fixação de complemento como prova confirmatória. Certamente contribuiu para isso o fato de a prova apresentar boa correlação com o isolamento de Brucella abortus de bovinos infectados (Hayes \& Chappel 1982, Sutherland et al. 1982, Corner et al. 1983).

Embora a técnica de fixação de complemento seja usada há muito tempo no diagnóstico da brucelose, ainda existem aspectos a serem esclarecidos; por exemplo, com relação ao antígeno utilizado. Mathias et al. (1991) compararam o antígeno de célula total e o lipopolissacáride de B. abortus e concluíram que o antígeno constituído por célula total da bactéria proporcionou maiores títulos de anticorpos, embora tenham observado que o antígeno solúvel também permite a obtenção de bons resultados.

Utiliza-se nesse teste o mesmo antígeno empregado na prova de soroaglutinação lenta em tubos, porém não foi possível encontrar na literatura estudos sobre a estabilidade do antígeno para uso na prova de fixação de complemento, de modo a estabelecer um prazo de validade para o mesmo, embora a legislação brasileira estabeleça um prazo de validade de até 18 meses para os antígenos usados nas provas para diagnóstico da brucelose animal (Brasil 2004). Assim sendo, esta investigação teve por objetivo avaliar a estabilidade do antígeno de célula total de Brucella ao longo do tempo, conservado sob refrigeração, para uso na reação de fixação de complemento.

\section{MATERIAL E MÉTODOS}

\section{Seleção dos soros sangüíneos utilizados}

Foram escolhidos 167 soros bovinos com variados títulos de anticorpos fixadores de complemento contra Brucella abortus. 


\section{Reação de fixação de complemento}

Soros. Antes do teste, os soros sanguíneos foram diluídos a 1/2 em tampão trietanolamina e submetidos a tratamento térmico em banho-maria a $58^{\circ} \mathrm{C}$ por 30 minutos, a fim de inativar complemento porventura ainda existente.

Antígenos. Foram analisadas 14 partidas de antígeno, preparado com B. abortus amostra 1119/3 e padronizado pelo fabricante para uso na prova de soroaglutinação lenta em tubos para diagnóstico sorológico da brucelose animal, com os seguintes tempos de fabricação: 23 anos e 11 meses, 21 anos e 4 meses, 18 anos e 5 meses, 14 anos e 10 meses, 10 anos, 8 anos e 3 meses, 7 anos e 2 meses, 5 anos e 7 meses. 4 anos e 3 meses, 3 anos e 2 meses, 2 anos e 3 meses, 1 ano e 8 meses, 1 ano e 1 mês, e 9 meses.

Cada partida de antígeno foi submetida a titulação em bloco, testando-se várias diluições do antígeno contra várias diluições de um soro com título moderado de anticorpos, para obter a diluição de reatividade ótima do antígeno, ou seja, aquela que proporciona a obtenção do maior título no soro testado. Os antígenos foram testados nas diluições 1:100, 1:150, 1:200, 1:250, 1:300, 1:400, 1:500, 1:600 e 1:800.

Para uso no trabalho, foi escolhida a diluição do antígeno que proporcionava o maior título do soro, porém sem a ocorrência de efeito prozona.

Complemento. Como complemento foi usada uma mistura de soros sangǘneos de várias cobaias, titulado como descrito por Alton et al. (1988), usando 20 vezes o volume empregado na microtécnica, para determinar o volume que continha uma unidade hemolítica $50 \%$. Para uso no teste, o complemento era diluído de modo a conter 5 unidades hemolíticas $50 \%$.

Sistema hemolítico. O sistema hemolítico era formado por uma suspensão de hemácias de carneiro, padronizada em espectrofotômetro para a concentração de $0,95 \mathrm{~g}$ de hemoglobina por $100 \mathrm{~mL}$, acrescida de igual volume de uma suspensão de hemolisina, que consiste de anticorpos de coelho contra hemácias de carneiro (Alton et al. 1988).

Técnica empregada. Foi empregada a microtécnica descrita por Alton et al. (1988), com incubação a $37^{\circ} \mathrm{C}$ por 30 minutos nas duas fases da reação.

O teste, realizado em placas de poliestireno de 96 cavidades com fundo em " $U$ ", consistia em colocar $25 \mu \mathrm{L}$ de soro, inativado em banhomaria a $58^{\circ} \mathrm{C}$ por 30 minutos, em diluições duplas, de $1 / 2$ até $1 / 256$, $25 \mu \mathrm{L}$ de antígeno e $25 \mu \mathrm{L}$ de complemento e incubar em estufa bacteriológica a $37^{\circ} \mathrm{C}$ por 30 minutos. Em seguida, eram acrescentados $25 \mu \mathrm{L}$ do sistema hemolítico, e, após agitação em agitador de microplacas, o material era novamente incubado nas condições mencionadas acima. Imediatamente após a incubação as placas eram colocadas na geladeira, para interromper a ação do complemento, sendo em seguida centrifugadas a $1.500 \mathrm{rpm}$ por 5 minutos. $O$ próximo passo consistia em realizar a leitura, comparando com uma escala de hemólise, observando-se o grau de fixação de complemento, com base na quantidade de hemácias restantes e no aspecto do sobrenadante.

Interpretação. $\mathrm{O}$ título obtido foi a recíproca da maior diluição do soro com pelo menos $25 \%$ de fixação de complemento, e foi considerado positivo o soro pelo menos $25 \%$ de fixação de complemento na diluição 1:4 (Alton et al. 1988).

\section{Análise estatística}

Os resultados obtidos com as diversas partidas de antígeno foram comparados com aqueles obtidos usando uma partida com nove meses de fabricação. Para essa comparação foram usados o teste de $\chi^{2}$ de McNemar (Jekel et al. 1999) e o coeficiente kappa, interpretado de acordo com os critérios mencionados por Pereira et al. (1995): kappa $<0,00=$ concordância ruim; kappa entre 0,00 e 0,20 = concordância fraca; kappa entre 0,21 e 0,40= concordância sofrível; kappa entre 0,41 e 0,60 = concordância regular; kappa entre 0,61 e $0,80=$ concordância boa; kappa entre 0,81 e $0,99=$ concordância ótima; kappa $=1$, concordância perfeita.

\section{RESULTADOS E DISCUSSÃO}

A diluição de reatividade ótima das diversas partidas de antígeno, ou seja, a diluição do antígeno que proporcionou maior título sorológico, encontra-se no Quadro 1, e por esses dados pode-se observar que essas diluições variaram de 1:200 a1:800, e é interessante ressaltar que a partida de antígeno que pôde ser usada mais diluída foi justamente aquela com maior tempo de fabricação, 23 anos e 11 meses. As menores diluições foram observadas na partida com 3 anos e 2 meses e, em seguida, na partida com 2 anos e 3 meses de fabricação. As duas partidas mais novas (13 e 14) apresentaram diluição de reatividade ótima de 1:500. Por isso, esses resultados sugerem ausência de relação entre o tempo de fabricação do antígeno e a diluição de reatividade ótima.

Estudos anteriores mostram que o antígeno de célula total de Brucella abortus proporciona resultados confiáveis quando usado na técnica de fixação de complemento para diagnóstico da brucelose bovina (Mathias et al. 1991). No entanto, observam-se variações entre diferentes partidas do antígeno quanto à diluição de reatividade ótima, como demonstram os dados observados no presente trabalho. É importante considerar que esse antígeno é elaborado para uso em provas de aglutinação, e, portanto, as avaliações realizadas pelo Ministério da Agricultura, Pecuária e Abastecimento para liberar as partidas de antígeno restringem-se ao desempenho do teste em provas de aglutinação, não sendo avaliado seu desempenho em provas de fixação de complemento (Brasil 2004).

O Quadro 2 apresenta os resultados obtidos com os treze antígenos avaliados, em comparação com os resultados obtidos com o antígeno com 9 meses de fabricação. São apresen-

Quadro 1. Diluição de reatividade ótima (DRO) e respectivo tempo de fabricação das diversas partidas de antígeno de célula total de Brucella abortus analisadas para o diagnóstico sorológico da brucelose pela reação de fixação de complemento

\begin{tabular}{ccc}
\hline Antígeno & Tempo de fabricação & DRO \\
\hline 1 & 23 anos e 11 meses & $1: 800$ \\
2 & 21 anos e 4 meses & $1: 600$ \\
3 & 18 anos e 5 meses & $1: 600$ \\
4 & 14 anos e 10 meses & $1: 500$ \\
5 & 10 anos & $1: 600$ \\
6 & 8 anos e 3 meses & $1: 600$ \\
7 & 7 anos e 2 meses & $1: 600$ \\
8 & 5 anos e 7 meses & $1: 500$ \\
9 & 4 anos e 3 meses & $1: 600$ \\
10 & 3 anos e 2 meses & $1: 200$ \\
11 & 2 anos e 3 meses & $1: 300$ \\
12 & 1 ano e 8 meses & $1: 400$ \\
13 & 1 ano e 1 mês & $1: 500$ \\
14 & 9 meses & $1: 500$
\end{tabular}


Quadro 2. Comparação entre os títulos obtidos na reação de fixação de complemento ao testar 167 soros bovinos com treze partidas de antígeno com diferentes tempos de fabricação e os títulos obtidos usando antígeno com nove meses de fabricação (Antígeno 14)

\begin{tabular}{|c|c|c|c|c|c|c|c|c|c|c|c|c|}
\hline \multirow[t]{2}{*}{ Antígeno } & \multicolumn{2}{|c|}{$\begin{array}{c}\text { Mesmo } \\
\text { título }\end{array}$} & \multicolumn{2}{|c|}{$\begin{array}{c}\text { Uma diluição } \\
\text { abaixo }\end{array}$} & \multicolumn{2}{|c|}{$\begin{array}{l}\text { Uma diluição } \\
\text { acima }\end{array}$} & \multicolumn{2}{|c|}{$\begin{array}{c}\text { Duas } \\
\text { abaixo }\end{array}$} & \multicolumn{2}{|c|}{$\begin{array}{c}\text { Duas } \\
\text { acima }\end{array}$} & \multicolumn{2}{|c|}{$\begin{array}{c}\text { Três } \\
\text { acima } \\
\end{array}$} \\
\hline & № & $\%$ & № & $\%$ & № & $\%$ & № & $\%$ & № & $\%$ & № & $\%$ \\
\hline 1 & 151 & 90,4 & 14 & 8,4 & 2 & 1,2 & 0 & 0 & 0 & 0 & 0 & 0 \\
\hline 2 & 147 & 88,0 & 5 & 3,0 & 15 & 9,0 & 0 & 0 & 0 & 0 & 0 & 0 \\
\hline 3 & 142 & 85,0 & 19 & 11,4 & 6 & 3,6 & 0 & 0 & 0 & 0 & 0 & . \\
\hline 4 & 133 & 79,6 & 33 & 19,8 & 1 & 0,6 & 0 & 0 & 0 & 0 & 0 & 0 \\
\hline 5 & 145 & 86,8 & 14 & 8,4 & 1 & 4,8 & 0 & 0 & 0 & 0 & 0 & 0 \\
\hline 6 & 142 & 85,0 & 24 & 14,4 & 1 & 0,6 & 0 & 0 & 0 & 0 & 0 & 0 \\
\hline 7 & 147 & 88,00 & 16 & 9,6 & 4 & 2,4 & 0 & 0 & 0 & 0 & 0 & - \\
\hline 8 & 145 & 86,8 & 22 & 13,2 & 0 & 0 & 0 & 0 & 0 & 0 & 0 & . \\
\hline 9 & 123 & 73,7 & 43 & 25,7 & 0 & 0 & 1 & 0,6 & 0 & 0 & 0 & \\
\hline 10 & 124 & 74,2 & 1 & 0,6 & 35 & 21,0 & 0 & 0 & 6 & 3,6 & 1 & 0,6 \\
\hline 11 & 126 & 75,4 & 1 & 0,6 & 37 & 22,2 & 0 & 0 & 3 & 1,8 & 0 & \\
\hline 12 & 147 & 88,0 & 10 & 6,0 & 10 & 6,0 & 0 & 0 & 0 & 0 & 0 & 0 \\
\hline 13 & 142 & 85,0 & 24 & 14,4 & 0,6 & 0 & 0 & 0 & 0 & 0 & 0 & 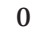 \\
\hline
\end{tabular}

Quadro 3. Comparação entre os resultados obtidos na reação de fixação de complemento ao testar 167 soros bovinos com treze partidas de antígeno com diferentes tempos de fabricação e os resultados obtidos usando antígeno com nove meses de fabricação (antígeno 14), adotando a diluição 1:4 como ponto-de-corte

\begin{tabular}{|c|c|c|c|c|c|c|c|}
\hline \multirow[t]{2}{*}{ Antígeno } & \multicolumn{2}{|c|}{$\begin{array}{c}\text { Resultados } \\
\text { concordantes }\end{array}$} & \multicolumn{2}{|c|}{$\begin{array}{c}\text { Resultados } \\
\text { discordantes }\end{array}$} & \multirow[t]{2}{*}{ Карра } & \multirow[t]{2}{*}{$\chi^{2}$} & \multirow[t]{2}{*}{$P$} \\
\hline & № & $\%$ & № & $\%$ & & & \\
\hline 1 & 163 & 97,6 & 4 & 2,4 & 0,96 & 0,25 & $>0,05$ \\
\hline 2 & 165 & 98,8 & 2 & 1,2 & 0,98 & 0,5 & $>0,05$ \\
\hline 3 & 158 & 94,6 & 9 & 5,4 & 0,9 & 1,78 & $>0,05$ \\
\hline 4 & 162 & 97,0 & 5 & 3,0 & 0,94 & 3,2 & $>0,05$ \\
\hline 5 & 161 & 96,4 & 6 & 3,6 & 0,92 & 0,17 & $>0,05$ \\
\hline 6 & 164 & 98,2 & 3 & 1,8 & 0,96 & 1,33 & $>0,05$ \\
\hline 7 & 163 & 97,6 & 4 & 2,4 & 0,96 & 0,25 & $>0,05$ \\
\hline 8 & 163 & 97,6 & 4 & 2,4 & 0,96 & 2,25 & $>0,05$ \\
\hline 9 & 162 & 97,0 & 5 & 3,0 & 0,94 & 3,2 & $>0,05$ \\
\hline 10 & 153 & 91,6 & 14 & 8,4 & 0,84 & 12,07 & $<0,01$ \\
\hline 11 & 157 & 94,0 & 10 & 6,0 & 0,88 & 4,9 & $<0,05$ \\
\hline 12 & 163 & 97,6 & 4 & 2,4 & 0,96 & 0,25 & $>0,05$ \\
\hline 13 & 163 & 97,6 & 4 & 2,4 & 0,96 & 2,25 & $>0,05$ \\
\hline
\end{tabular}

tados número e porcentagem de soros com o mesmo título quando testados com o antígeno analisado e com o antígeno de produção mais recente, e são também apresentadas as variações de título obtidas, em número de diluições.

É interessante notar que justamente o antígeno produzido há mais tempo (antígeno 1) foi o que apresentou maior proporção $(90,4 \%)$ de soros cujo título foi exatamente o mesmo obtido com o antígeno de fabricação mais recente. 0 antígeno com 4 anos e três meses foi o que apresentou menor proporção de soros com o mesmo título $(73,7 \%)$ observado com o antígeno mais recente. Além do fato de a grande maioria dos soros apresentar o mesmo título com o antígeno avaliado e com aquele usado como padrão, nota-se que as divergências, na grande maioria das vezes, restringiram-se a uma diluição, exceto o antígeno 9 , com o qual um $(0,6 \%)$ dos soros apresentou título duas diluições abaixo, $\mathrm{o}$ antígeno 10 (3 anos e 2 meses), com o qual seis $(3,6 \%$ ) soros apresentaram título duas diluições acima e um $(0,6 \%)$ apresentou título três diluições acima, e o antígeno 11 (2 anos e 3 meses), com o qual três $(1,8 \%)$ soros apresentaram título duas diluições acima (Quadro 2)

Quando se comparam os resultados após classificação em positivos e negativos adotando-se a diluição 1:4 como pontode-corte observa-se que o antígeno que apresentou maior proporção de resultados concordantes foi o 2 (21 anos e 4 meses), com $165(98,8 \%)$ resultados concordantes e apenas dois $(1,2 \%)$ discordantes, tendo apresentado a maior concordância, com um indicador kappa 0,98 . Em seguida, $o$ antígeno 6 (8 anos e 5 meses), com $164(98,2 \%)$ resultados concordantes com os obtidos com o antígeno 14 e três $(1,8 \%)$ discordantes. $\mathrm{O}$ antígeno de fabricação mais antiga entre os avaliados (Antígeno 1, com 23 anos e 11 meses) apresentou 163 (97,6\%) resultados concordantes com aqueles obtidos com o antígeno mais novo e kappa 0,96 , ou seja, concordância ótima. 0 antígeno com menor proporção de resultados concordantes foi o 10 (3 anos e 2 meses), com $153(91,6 \%$ ) soros, e maior proporção de discordantes $(8,4 \%)$, sendo também o que apresentou menor indicador kappa $(0,84)$, seguido pelo antígeno 11 ( 2 anos e 3 meses), com 157 (94,0\%) resultados concordantes e $10(6,0 \%)$ discordantes, e indicador kappa 0,88. Mesmo assim os resultados obtidos com esses dois antígenos apresentaram concordância ótima em relação aos resultados obtidos com o antígeno adotado como padrão, ou seja, indicador kappa entre 0,81 e 0,99 (Quadro 3). Esses dois antígenos foram os únicos cujos resultados diferiram significativamente daqueles obtidos com o antígeno mais recente, pelo teste de $\chi^{2}$ de McNemar ( $\mathrm{P}<0,01$ e $\mathrm{P}<0,05$, respectivamente).

Pela observação dos dados expostos acima se constata que a grande maioria dos soros apresentou resultados muito parecidos quando testados pela fixação de complemento usando as diversas partidas de antígeno avaliadas. Constata-se também que as eventuais divergências observadas não guardam relação com o tempo de fabricação do antígeno, uma vez que os resultados obtidos com antígenos fabricados há mais de 20 anos apresentaram concordância ótima com os resultados proporcionados por antígeno de fabricação mais recente. Dessa forma, os resultados obtidos no presente estudo não amparam o prazo de validade de 18 meses após o envase do antígeno, pelo menos para uso na reação de fixação de complemento, adotado pelo Ministério da Agricultura, Pecuária e Abastecimento (Brasil 2004).

Esses dados permitem concluir que a grande maioria dos soros apresentou resultados muito próximos quando testados pela reação de fixação de complemento usando as diversas partidas de antígeno de $B$. abortus avaliadas e que não se observou relação entre tempo de fabricação do antígeno e diferenças nos resultados obtidos na reação de fixação de complemento.

\section{REFERÊNCIAS}

Alton G.G., Jones L.M., Angus R.D. \& Verger J.M. 1988. Techniques for the Brucellosis Laboratory. Institut National de la Recherche Agronomique, Paris. 190p.

Brasil 2001. Instrução Normativa No.2, de 10 de janeiro de 2001, institui o 
Programa Nacional de Controle e Erradicação da Brucelose e Tuberculose Animal e dá outras providências. Diário Oficial da República Federativa do Brasil, Poder Executivo, Brasília, DF, 16 de janeiro de 2001, Seção 1, p.1117.

Brasil 2004. Instrução Normativa no.15, de 19 de fevereiro de 2004, aprova o Regulamento Técnico para produção e controle de qualidade da vacina contra brucelose e antígenos para diagnóstico da brucelose. Diário Oficial da União da República Federativa do Brasil, Poder Executivo, Brasília, DF, 24 de março de 2004, Seção 1, p.25-26.

Corner L.A., Alton G.G., McNichol L.N., Streetens T. \& Trueman K.F. 1983. An evaluation of an anamnestic test for brucellosis in cattle of the northern pastoral areas. Aust. Vet. J. 60:1-3.

Dajer A., Luna-Martinez E., Zapata D., Villegas S., Gutierrez E., Pena G., Gurria F., Nielsen K. \& Gall D. 1999. Evaluation of a fluorescence polarization assay for the diagnosis of bovine brucellosis in Mexico. Prev. Vet. Med. 40:6773.

Hayes J. \& Chappel R.J. 1982. A comparison of the results of the brucellosis radioimmunoassay and other serological tests in experimentally infected cattle. J. Hyg. 88:21-28.

Jekel J.F., Elmore J.G. \& Katz D.L. 1999. Epidemiologia, Bioestatística e Medicina Preventiva. Artmed, Porto Alegre. 328p.

MacMillan A.P., Greiser-Wilke I., Moennig V. \& Mathias L.A. 1990. A competitive enzyme immunoassay for brucellosis diagnosis. Dtsch. Tierärztl. Wochenschr. 97: 83-85.

Mathias L.A., Alberto L.H., Roxo E., Perecin D. \& Girio R.J.S. 1991. Avaliação de uma microtécnica de fixação de complemento no diagnóstico sorológico da brucelose bovina e comparação entre os antígenos particulado e lipopolissacáride. Ars Vet., Jaboticabal, 7: 38-48.

McGivem J.A., Tucker J.D., Perrett L.L., Stack J.A., Brew S.D. \& MacMillan A.P. 2003. Validation of FPA and cELISA for the detection of antibodies to Brucella abortus in cattle sera and comparison to SAT, CFT, and iELISA. J. Immunol. Methods 278:171-178.

Nielsen K., Kelly L., Gall D., Nicoletti P. \& Kelly W. 1995. Improved competitive enzyme immunoassay for the diagnosis of bovine brucellosis. Vet. Immunol. Immunopathol. 46:285-291.

Nielsen K., Gall D., Jolley M., Leishman G., Balsevicius S., Smith P., Nicoletti P. \& Thomas F. 1996. A homogeneous fluorescence polarization assay for detection of antibody to Brucella abortus. J. Immun. Methods 195:161-168.

Nielsen K., Gall D., Lin M., Massangill C., Samartino L., Perez B., Coats M., Hennager S., Dajer A., Nicoletti P. \& Thomas F. 1998. Diagnosis of bovine brucellosis using a homogeneous fluorescence polarization assay. Vet. Immunol. Immunopathol. 66:321-329.

Pereira M.G. 1995. Epidemiologia, Teoria e Prática. Guanabara Koogan, Rio de Janeiro. 596p.

Poester F.P., Gonçalves, V.S.P. \& Lage A.P. 2002. Brucellosis in Brazil. Vet. Microbiol. 90:55-62.

Samartino L., Gregoret R., Gall D. \& Nielsen K. 1999. Fluorescence polarization assay: application to the diagnosis of bovine brucellosis in Argentina. J. Immunoassay. 20:115-126.

Sutherland S.S., Le Gras D.V., Robertson A.G., Johnston J.M. \& Evans R.J. 1982. Serological response of cattle after vaccination and challenge with Brucella abortus. Vet. Microbiol. 7:165-175. 